TP Periodica Polytechnica Electrical Engineering and Computer Science

60(4), pp. 254-260, 2016

DOI: $10.3311 /$ PPee. 10020

Creative Commons Attribution (i)

RESEARCH ARTICLE

\section{Reducing Solar Dish Park Production Volatility Utilizing Lithium-ion Batteries}

\author{
Konstantinos Brellas $^{1 *}$, Antonios Tsikalakis ${ }^{2}$, Kostas Kalaitzakis ${ }^{1}$
}

Received 10 June 2016; accepted 23 August 2016

\begin{abstract}
Solar dish-Stirling technology is the Concentrated Solar Power (CSP) technology that can be more easily integrated into Distribution networks due to its small size. However, a disadvantage of this technology is that features shorter thermal inertia and thus, the output is more volatile compared to large scale CSP plants. In this paper, the production of a solar dish-Stirling plant connected to a battery bank forming a Hybrid plant is studied, in order to determine up to what extent the production stabilization can be achieved. A modelling approach of the electricity output of a solar dish system integrated to a lithium-ion battery, is developed. A methodology based on the minimization of the mean square error between the actual and the proposed stabilized production is presented, in order to optimally size the battery bank. Results from the application of the Hybrid plant for typical days of various seasons prove the output capability of such a configuration and the guaranteed power amount of the relevant plant, along with the addition of volatility decrease.
\end{abstract}

\section{Keywords}

solar thermal, concentrated solar power, CSP, solar dish, Stirling engine, lithium-ion batteries

\footnotetext{
${ }^{1}$ Technical University of Crete

${ }^{2}$ Hellenic Electricity Distribution Network Operator S.A.

*Corresponding author, e-mail: kostasmprls@gmail.com
}

\section{Introduction}

Solar thermal power production by means of Concentrated Solar Power (CSP) units are gaining popularity as reliable Renewable Energy Source (RES) units, because they have the capability of greater power production, higher power density (approximately 40-45\% more than a PV park) [1] and more stable output.

One of their interesting characteristics is their capability to stabilize their output with the addition of thermal storage or extra power production from a conventional thermal unit like in North Africa countries [2]. Thus, their production can be considered available to provide capacity credit to the upstream power system, featuring the ability to effectively substitute the production of conventional power production units. This replacement is going to make the power production not only more eco-friendly but cheaper as well in the near future.

The solar dish-Stirling is a CSP technology invented in the 80 s but effectively developed in the $00 \mathrm{~s}$. A solar dish system consists of a parabolic collector that collects the solar radiation on a specific spot. A thermal receiver placed on the spot concentrates the thermal power from the solar radiation. This concentrated thermal power is transferred to the Stirling engine chamber, where it is transformed into electricity. In Fig. 1 the components of a solar dish-Stirling system are displayed [2].

All the components of the solar dish-Stirling system are depended to each other, but the operation of one differs a lot from the other, as each one has a very specific role to the whole system. Furthermore, solar dish systems use solar tracker systems to track the best solar azimuth angle and thus maximize their efficiency.

Solar dish systems have relatively low power production, as their maximum production reaches about $25 \mathrm{~kW}$, but they can be easily combined together to form a solar thermal park. Such ability allows CSPs consisting of Solar-Dishes to be actually considered as Distributed Generation Units, compared to the rest CSP technologies developed so far; in addition, such parks require more scattered space. Therefore, this kind of parks can be interconnected also in smaller island power systems.

A common disadvantage of CSP units is that production is not as stable as in a conventional thermal power plant and the 
production depends solely on the weather conditions, unless suitable storage is utilized. The low output capacity of solar dishes allows much easier integration of battery storage, compared to MW scale CSPs currently built around the world. [3]

In this paper an operating mode of a Hybrid Battery- Stirling Solar dish plant, reducing the volatility of the Stirling Solar Dish output, is suggested. The hybrid solar plant consists of a lithium-ion battery bank installed alongside the park, in order to reduce power production volatility. When the solar park produces excessive power, the surplus electricity is stored in the battery bank. The battery energy is used to level potential losses of power production of the plant at another time.

In Section 2, the modeling of the solar dish-Stirling is described, providing a power production prediction. In Section 3, the battery bank behavior is modeled, so as to implement the volatility reduction algorithms than are explained in Section 4. Finally, in Section 5, the results of the simulations are presented with some evaluation of the results in real applications by power producers.

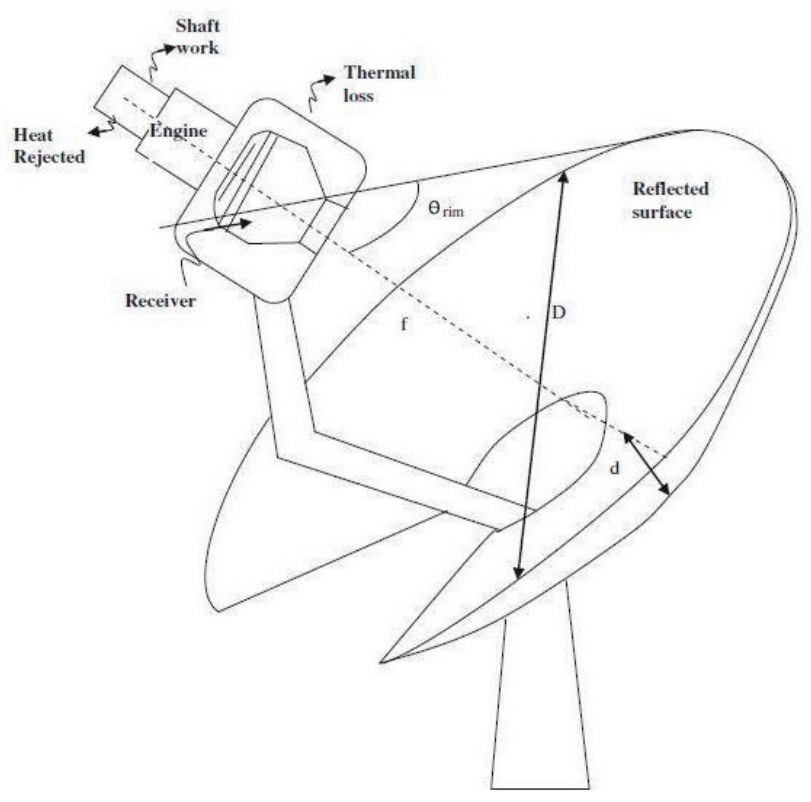

Fig. 1 Solar dish-Stirling

\section{Modelling of solar dish with Stirling Engine}

The solar thermal park modeled is of $1 \mathrm{MW}$ nominal power output. The park consists of 40 solar dish-Stirling CSPs of $25 \mathrm{~kW}$ nominal capacity each, costing about $2000-3000 € / \mathrm{kW}$ [4]. To simplify modeling, these disks are assumed of the same operation principle. Therefore, after modeling one solar dishStirling CSP, the power production prediction is multiplied by 40 , in order to obtain the total power production of the park.

The modelling of the solar dish-Stirling system is implemented in three stages, considering each stage connected to the next one and so on. The first stage is the parabolic collector, the next one is the thermal receiver and the last is the Stirling engine. The solar dishes are placed inside the solar thermal park as shown in Fig. 2.

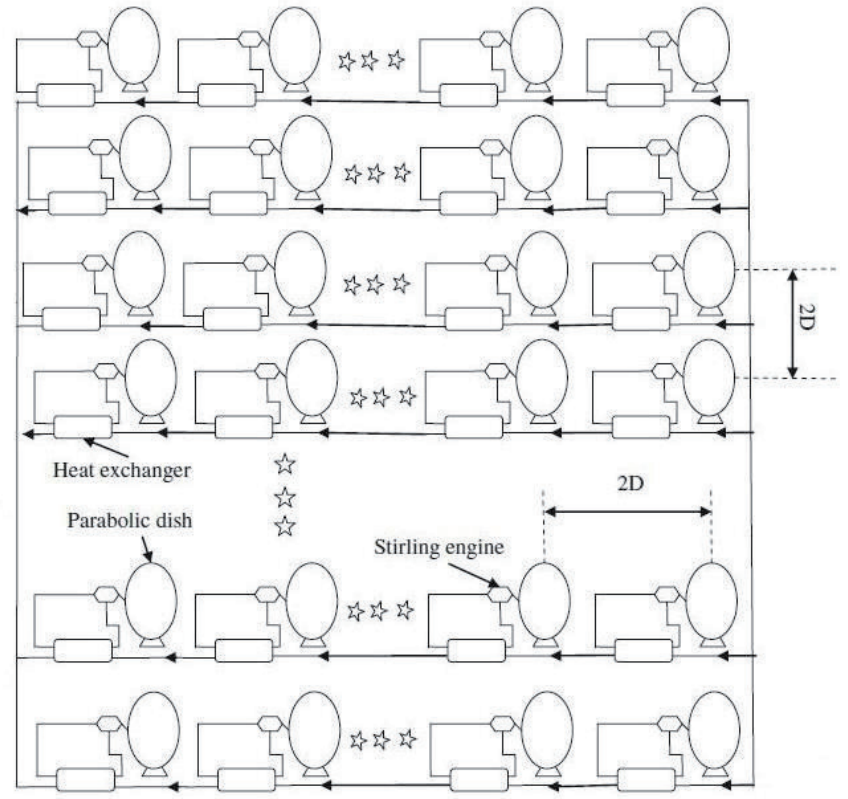

Fig. 2 Placement of solar dishes in solar thermal park

\subsection{Parabolic Collector}

In order to find the energy from the sun received by the parabolic collector, which afterwards is converted into electricity, the following solar geometry parameters must be calculated [5]:

$\delta$ - declination angle

$$
\delta=23.45 \cdot \sin \left(360 \cdot \frac{284+n}{365}\right)
$$

where $n$ represents the current day of the year. For example, January $1^{\text {st }}$ is the first day of the year, while February $1^{\text {st }}$ is the $32^{\text {nd }}$ day of the year and so on.

\section{$E$ - Time parameter}

This parameter determines the impact the solar radiation throughout the year. It is calculated by Eq. (2):

$$
\begin{gathered}
E=229.199 \cdot(0.00075+0.001868 \cdot \cos (B)-0.032077) \cdot \sin (B) \\
-0.014615 \cdot \cos (2 \cdot B)-0.04089 \cdot \sin (2 \cdot B) \\
B=(n-1) \cdot \frac{360}{365}
\end{gathered}
$$

where $n$ is the current day of the year.

\section{Solar time}

The Solar Time parameter is used to determine the time during which a place has sunshine, depending on the position of the sun on the sky. The Solar Time is calculated by Eq. (4):

$$
\text { SolarTime }=\text { Time }+\frac{L_{s t}-L_{l o c}}{15}+\frac{E}{60}
$$

where:

Time - time of the day 
$L_{s t}-$ longitude

$L_{l o c}$ - equatorial reference

$E$ - Time parameter

$\omega$ - relative solar time

This parameter expresses the time from the solar perspective and is calculated by Eq. (5):

$$
\omega=(\text { SolarTime }+12) \cdot 15
$$

Where SolarTime is the parameter derived by Eq. (4).

$\theta_{z}$ - azimuth angle

The azimuth angle is the angle between the solar rays and the horizontal ground and it's calculated in Eq. (6):

$$
\cos \theta_{z}=\sin \phi \cdot \sin \delta+\sin \phi \cdot \sin \delta \cdot \cos \omega
$$

where:

$\varphi$ - latitude

$\delta$ - declination angle from Eq. (1)

$\omega$ - relative solar time from Eq. (5)

$\theta$ - collector angle

This parameter describes the angle between the solar rays and the leveled parabolic collector and is calculated by Eq. (7):

$$
\begin{aligned}
\cos \theta= & \sin \delta \cdot \sin \phi \cdot \cos \beta-\sin \delta \cdot \cos \phi \cdot \sin \beta \cdot \cos \theta_{z} \\
& +\cos \delta \cdot \cos \phi \cdot \cos \beta \cdot \cos \omega \\
& +\cos \delta \cdot \sin \phi \cdot \sin \beta \cdot \cos \theta_{z} \cdot \cos \omega \\
& +\cos \delta \cdot \sin \beta \cdot \sin \theta_{z} \cdot \sin \omega
\end{aligned}
$$

where all the parameters have been defined above.

Having all the solar parameters, the solar radiation concentrated by the parabolic collector is calculated by Eq. (8):

$$
Q_{a}=I_{b} \cdot A_{g} \cdot \cos \theta \cdot \gamma_{r} \cdot I F \cdot n_{d}
$$

where:

$Q_{a}-$ the concentrated solar radiation

$I_{b}-$ direct solar radiation

$A_{g}-$ collector surface

$\cos \theta$ - collector angle (if the solar dish has a azimuth tracking system then $\cos \theta=1$ )

$\gamma_{r}-$ collector reflectivity $\left(\gamma_{r} \sim=0.92\right)$

$I F-$ reflectivity parameter $(I F \sim=0.92)$

nd - loses due to dust $\left(n_{d} \sim=0.98\right)$

Employing Eq. (8), the solar radiation concentrated by the parabolic collector of a solar dish CSP, is calculated. This amount of energy is forwarded to the thermal receiver in order to be transformed to thermal energy.

\subsection{Thermal Receiver}

The thermal receiver of a solar dish-Stirling CSP is located to the focal point of the parabolic collector and collects the thermal energy of the solar rays. The total energy output of the thermal receiver is reduced by the energy losses. These losses are divided in two categories: losses due to energy transformation and radiation losses. [6]

Losses due to energy transformation are calculated by Eq. (9):

$$
Q_{\text {conv }}=h_{\text {total }} \cdot A_{\text {cav }} \cdot\left(T_{\text {cav }}-T_{a}\right)
$$

where:

$A_{c a v}$ - receiver surface

$T_{c a v}$ - receiver temperature

$T_{a}-$ environment temperature

$$
h_{\text {total }}=h_{\text {natural }}+h_{\text {forced }}
$$

where:

$h_{\text {natural }}$ - natural thermal energy transfer constant

$h_{\text {forced }}-$ forced thermal energy transfer constant

The $h_{\text {natural }}$ parameter depends on the area the solar park is and the local temperature, where $h_{\text {forced }}$ depends on the wind velocity and is calculated by Eq. (11):

$$
h_{\text {forced }}=0.1967 \cdot V_{w}^{1.849}
$$

where $V_{w}$ is the wind velocity.

The radiation losses are split in two subcategories: losses due to reflectivity and losses due to emition. The losses due to reflectivity are calculated by Eq. (12):

$$
Q_{\mathrm{rad} \operatorname{Refl}}=\left(1-a_{\text {eff }}\right) \cdot Q_{a}
$$

where:

$a_{\text {eff }}$ - receiver radiation absorptivity

$Q_{a}$ - energy collected in parabolic collector

The losses due to emition are calculated by Eq. (13).

$$
Q_{\text {radEmit }}=\varepsilon_{\text {eff }} \cdot A_{\text {cav }} \cdot\left(T_{c a v}^{4}-T_{a}^{4}\right)
$$

where:

$\varepsilon_{\text {eff }}-$ receiver absorptivity factor $(\sim=0.98)$

$A_{\text {cav }}$ - receiver surface

$T_{\text {cav }}$ - receiver temperature

$T_{a}$ - environment temperature

The total losses regarding the thermal receiver are calculated by Eq. (14):

$$
Q_{\text {loss }}=Q_{\text {conv }}+Q_{\text {rad }}
$$

The total energy output of the thermal receiver, which is directed to the Stirling engine, is calculated by Eq. (15):

$$
Q_{u}=Q_{a}-Q_{\text {loss }}
$$




\subsection{Stirling Engine}

The Stirling engine, which is connected to the thermal receiver directly, receives the energy from the thermal receiver calculated in Eq. (15). Due to the complexity of thermodynamic modelling, the efficiency of the Stirling engine is not modeled but approximated to $38 \%$, which is an average value for such an engine. [6] The total power produced by the Stirling engine is calculated by Eq. (16):

$$
W=n_{\text {load }} \cdot Q_{u} \cdot n_{\text {al }}
$$

where:

$n_{\text {load }}-$ Stirling engine efficiency $(=0.38)$

$Q_{u}$ - energy input to the engine

$n_{a l}-$ efficiency of converter $(=0.98)$

All the above equations assure a power production prediction of the solar thermal park for every hour of the year. In Table 1, all the parameters used, which do not depend on the inputs of the system, along with their values, are listed.

Table 1 Constant parameters and their values

\begin{tabular}{ll}
\hline Symbol & Value \\
\hline Focal length $L$ & $7.45(\mathrm{~m})$ \\
Collector surface $A_{g}$ & $87.67\left(\mathrm{~m}^{2}\right)$ \\
Mirror reflectivity $\gamma_{r}$ & 0.92 \\
Absorptivity factor $I F$ & 0.92 \\
dust losses factor $n_{d}$ & 0.98 \\
cavity diameter $A_{c a v}$ & $0.45(\mathrm{~mm})$ \\
Cavity absorptivity $a_{c a v}$ & 0.96 \\
cavity emissivity $e_{e f f}$ & 0.9 \\
longitude $L_{\text {loc }}$ & $24.018\left({ }^{\circ}\right)$ \\
equatorial reference $L_{s t}$ & $30\left(^{\circ}\right)$ \\
latitude $F$ & 35.51 \\
receiver surface $A_{c a}$ & $0.2\left(\mathrm{~m}^{2}\right)$ \\
Stirling engine efficiency $n_{\text {load }}$ & 0.385 \\
Boltzmann constant $s$ & $5.67 * 10^{-8}$ \\
converter efficiency $n_{a l}$ & 0.98 \\
\hline
\end{tabular}

\section{Batteries}

In order to reduce power production volatility of the park, installation of a battery bank is proposed. It is important to note that the battery bank in not necessarily installed within the solar thermal park, but they combination acts as one controlled entity. The main goal for this energy exchange is to reduce production volatility and achieve a production level closer to the average production of the solar thermal park. Thus, the battery bank is charged when the production from the solar thermal park is higher than the daily average production and is discharged when the production of the solar thermal park is lower. The battery bank consists of lithium-ion batteries of the Sanyo DCB-102 type characteristics, which are shown in Table 2. [7, 8]

Table 2 Sanyo DCB-102 characteristics

\begin{tabular}{ll}
\hline Symbols & Value \\
\hline battery capacity $\mathrm{C}_{\text {bat }}$ & $1.59 \mathrm{kWh}$ \\
maximum discharge power $\mathrm{P}_{\text {max-dis }}$ & $-340 \mathrm{~W}$ \\
maximum charge power $\mathrm{P}_{\text {max-ch }}$ & $720 \mathrm{~W}$ \\
nominal voltage $\mathrm{V}_{\mathrm{dc}}$ & $48 \mathrm{~V}$ \\
price & $1000 € / \mathrm{kWh}$ \\
Inverter price & $150 € / \mathrm{W}$ \\
\hline
\end{tabular}

The battery bank can have only three states, operating in one of them at any specific time [8]. These states are: (a) the charging state, (b) the discharging state and (c) the idle state. When the battery is being charged, its operation is described by Eqs. (17)-(19):

$$
\begin{gathered}
I_{b a t}(t)=\min \left(I_{\max }, \frac{S O C_{\max }-S O C(t-1) \cdot \frac{C_{b a t}}{U_{d c}}, \frac{P_{\text {load }}(t) \cdot n_{a c d c}}{U_{d c}}, \frac{P_{b i d i}}{U_{d c}}}{d t}\right. \\
P_{b a t_{c} c h}=I_{b a t}(t) \cdot U_{d c} \\
\operatorname{SOC}(t)=S O C(t-d t)+\frac{I_{b a t}(t) \cdot d t \cdot n_{b a t \_c h}}{C_{b a t} / U_{d c}}
\end{gathered}
$$

where:

$I_{b a t}$ - charge current of battery

$P_{\text {bat_ch }}-$ charge power of battery

$I_{\max }$ - maximum charge current (produced by Pmax-ch)

$S O C$ - State Of Charge

$C_{b a t}$ - battery capacity

$U_{d c}-$ DC channel voltage

$n_{\text {acdc }}-$ ac-dc conversion efficiency

$P_{\text {bidi }}$ - bi-directional converter efficiency

$n_{\text {bat_ch }}-$ charge of battery efficiency

$d_{t}$ - time frame between two calculations $(=1 \mathrm{~h})$

When the battery is being discharged, its operation is described by Eqs. (20)-(22):

$$
\begin{aligned}
& I_{b a t}(t)=\min \left(I_{\max }, \frac{\left(S O C(t-1)-S O C_{\min }\right) \cdot \frac{C_{\text {bat }}}{U_{d c}}}{d t}, \frac{P_{\text {load }}(t)}{U_{d c} \cdot n_{d c a c}}, \frac{P_{b i d i}}{U_{d c} \cdot n_{d c a c}}\right) \\
& P_{b a t_{\text {dis }}}=I_{b a t}(t) \cdot U_{d c} \\
& \operatorname{SOC}(t)=\operatorname{SOC}(t-d t)-\frac{I_{b a t}(t) \cdot d t \cdot n_{b a t \_\mathrm{dis}}}{C_{b a t} / U_{d c}}
\end{aligned}
$$


where the same parameters are used as before, plus the next:

$P_{b a t \text { dis }}$ - discharge power of battery

$n_{\text {dcac }}-$ dc-ac conversion efficiency

$n_{\text {bat_dis }}-$ battery discharge efficiency

$S O C_{\min }-$ lowest charge state of battery

When the battery is not used and is in its idle state, its operation is described by Eq. (23):

$$
\operatorname{SOC}(t)=\operatorname{SOC}(t-d t) \cdot(1-d)
$$

where $d$ is the self-discharge constant of the battery. The parameters featuring constant values are displayed in Table 3.

Table 3 Parameter values of battery bank

\begin{tabular}{ll}
\hline Symbols & Values \\
\hline maximum state of charge $S O C_{\max }$ & 1 \\
Minimum state of charge $S O C_{\min }$ & 0.2 \\
$a c$ to $d c$ conversion efficiency $n_{a c-d c}$ & 0.97 \\
$d c$ to $a c$ conversion efficiency $n_{d c-a c}$ & 0.96 \\
charging efficiency $n_{\text {bat-ch }}$ & 0.95 \\
discharging efficiency $n_{\text {bat-dis }}$ & 0.95 \\
\hline
\end{tabular}

\section{Operation Algorithms}

The behaviour and operation of each component of the Hybrid solar thermal park is described in the previous sections. Here the proposed algorithms developed to achieve the optimal energy distribution between the solar dishes and the battery bank, along with optimal sizing the battery bank capacity are described.

\subsection{Algorithm for solar park volatility reduction}

As a first step towards the optimal operation of the solar park, an algorithm that reduces the production volatility as much as possible is proposed. This algorithm aims towards the optimum management of energy produced by the solar park, to ensure higher capacity credit, which, in turn, can be remunerated according to the Grid codes [9]. To achieve higher efficiency, the algorithm tries to reduce volatility in a day by day scenario.

By reducing volatility the owner of the solar thermal park can gain many benefits, such as more operating paying hours and confirmed capacity credit, as long as biding higher during the hours that ensure the highest prices. The algorithm for reducing power production volatility operates in two stages. In the first stage, the algorithm computes the expected mean value of power production for the specific day. If the actual production is higher than the mean value, then the excessive energy is used to charge the batteries. If the actual production is lower than the mean value then the batteries' power is used to cover the difference. In the second stage, the mean squares error method is used in order to ensure that the volatility reduction converges near optimal. In this stage, the actual production and the production calculated in the first stage are compared and, employing Least Squares Error minimization techniques, the production minimization of the mean square error is calculated. The production derived after the second stage of the algorithm satisfies the technical requirements of the problem and is the best production volatility reduction that can be achieved. In Fig. 3 the flow diagram of the algorithm is shown.

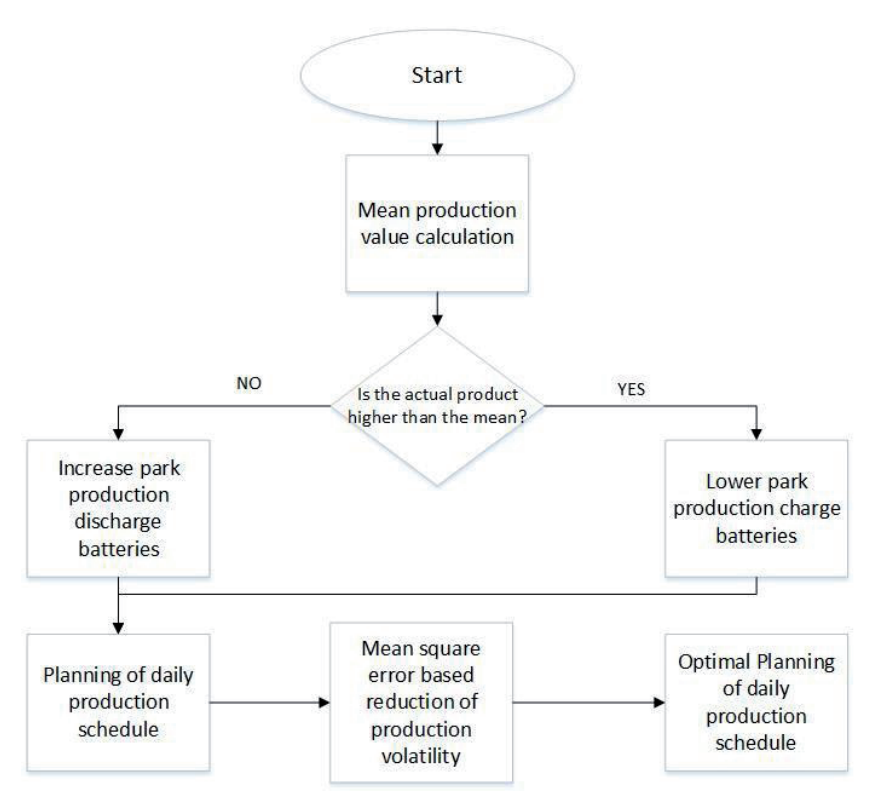

Fig. 3 Algorithm for production volatility reduction

\subsection{Battery bank sizing algorithm - a case study}

Based on the algorithm described in the previous section, there is a way to smoothen the production of the solar dish thermal park and, furthermore to elaborate a mechanism assuring that production volatility is reduced and a capacity credit can be achieved.

To derive the battery size necessary for the algorithm operation, the maximum difference between the actual and the optimized operation is computed. This difference dictates the size of the battery bank that is essential for the algorithm operation.

The capacity of the battery bank is the maximum difference in power between the real production and the proposed one, within an hour. For the present case study, the maximum difference resulting within an hour is approximately $700 \mathrm{~kW}$. So the battery bank must feature a $700 \mathrm{kWh}$ capacity in order to eliminate this maximum difference. This battery bank can be formed with various battery strings connections. The goal here is to find the minimum number of batteries that can fulfill the needs of the system, thus ensuring the lower cost. The requirements of the proposed system are not only the power bank capacity and the scheduling fast response, but also the dc to ac converter characteristics.

The bi-direction converter from dc to ac and vice versa, for the present case study, is rated to a power capacity of $700 \mathrm{~kW}$ [6], but its voltage range varies for 480 to $600 \mathrm{~V}$. Regarding 
the voltage range, there can be 11-13 batteries in a row, as the nominal voltage of one battery is $48 \mathrm{~V}$.

The algorithm operation concept is to check every possible combination of battery topology and discover the least expensive one. Subsequently, taking into consideration the restrictions mentioned above, the economic impact on the solar thermal plant of every possible topology is calculated and the least costly topology is derived.

After the evaluation of all possible outcomes, the algorithm suggests the minimum number of batteries to 12 in a row with 37 rows of them. Except for the consideration to cover 100\% of the production difference mentioned above, the considerations to cover $80 \%$ and $60 \%$ are examined. For the $80 \%$ case a combination of 12 batteries in a row with 28 rows is required, while for the $60 \%$ case a combination of 11 batteries in a row with 25 rows is required.

\section{Results and Conclusion}

In the previous sections, the modeling of the solar thermal park, the production prediction and the optimal sizing and connection of the batteries have been presented. In this section, the difference between the output of the Hybrid Solar-Thermal Park and the output of the Solar Thermal Park alone is computed exploiting the proposed algorithm.

Focus is given on the comparison of the output between the "proposed" operation and the expected operation based on actual solar data from the meteorological station at the Technical University of Crete.

The production volatility reduction expectation is that the 'proposed' production should give graphs that present much lower peak-to-peak values compared to the 'real' one. In a given time period, it is easier to extract conclusions about how much more efficient is the smoothing of the production. It is important to note here that the smoothing of the production occurs only during the hours of a day with sunshine.

In the following figures the exchange to/from the battery bank and the hourly limits for charging and discharging the battery are shown for each example. These limits not only do they take into account the battery characteristics as presented in Table 2, but also the state of charge of the battery as a result of the proposed algorithm.

Examining days throughout a year, a typical day for winter was picked that is the first day of the year also. A shown in Fig. 4, it is obvious that the production stabilization is far more visible than before and also provides capacity credit equal to $120 \mathrm{~kW}$.

Since the January 1 st was one of the lowest production days of the year, the production of a day in December is presented, with lower cloudiness than 1st of January. In Fig. 5, the production volatility reduction, as long as the capacity credit, which is $200 \mathrm{~kW}$, is highly achievable as long as the volatility reduction is more prominent.
Examples for the volatility reduction during a spring day and a summer day are shown in Fig. 6, and Fig. 7, respectively. In these examples the capacity credit factor achieved is $200 \mathrm{~kW}$ and $250 \mathrm{~kW}$ respectively, while after the second hour of sunshine the production is stabilized to $500 \mathrm{~kW}$ and $570 \mathrm{~kW}$ respectively before dropping again in the afternoon hours.

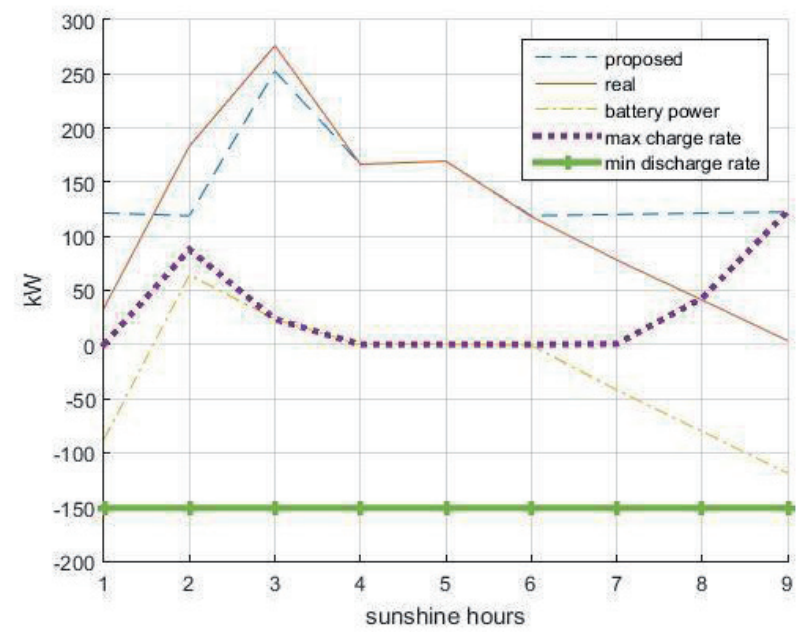

Fig. 4 Production comparison for January $1^{\text {st }}$

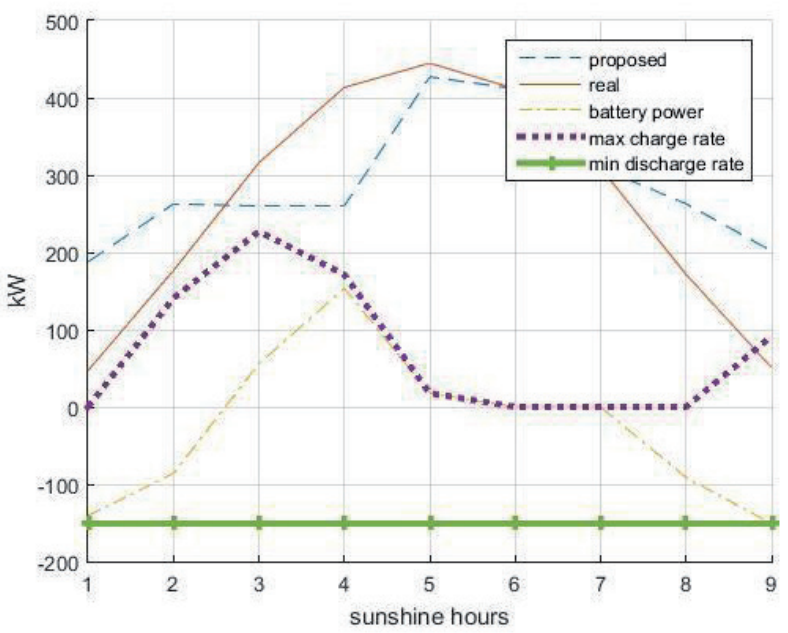

Fig. 5 Comparison of production in a winter day

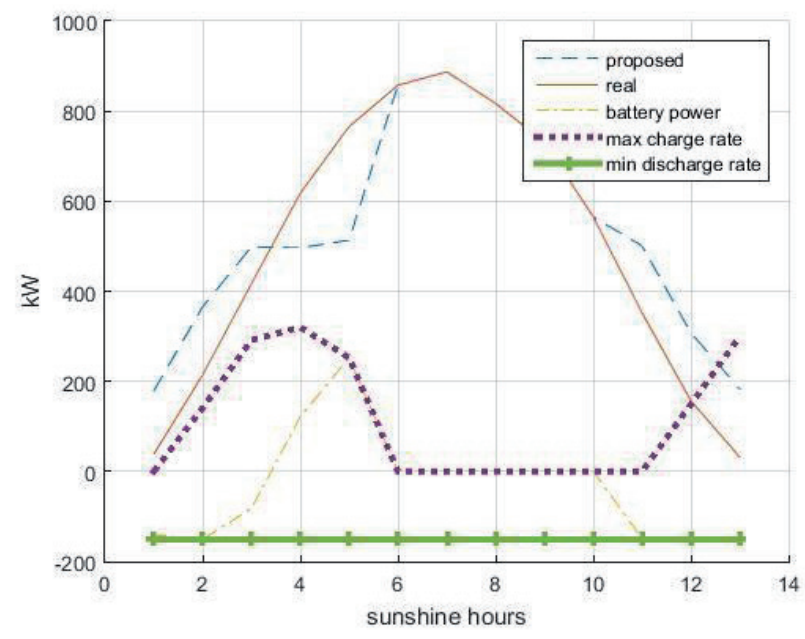

Fig. 6 Comparison of production in a spring day 


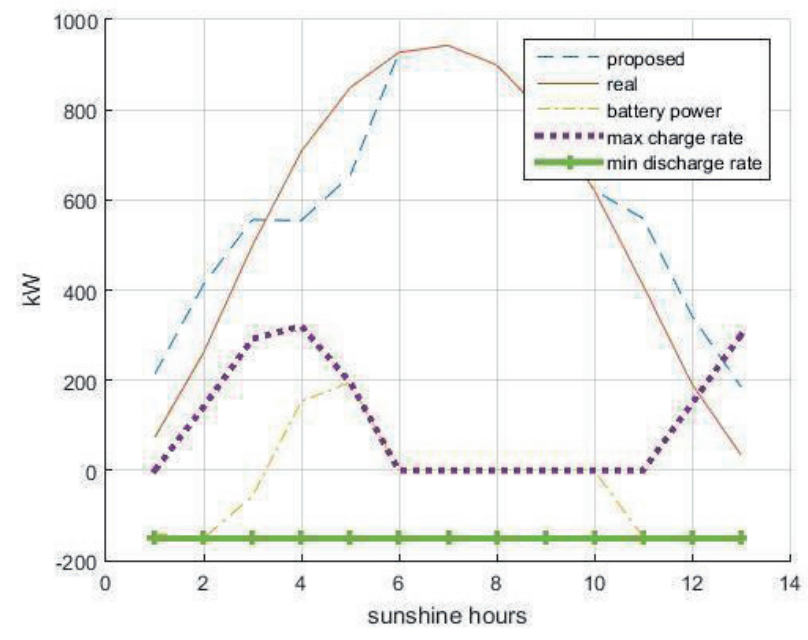

Fig. 7 Comparison of production in a summer day

Finally, an example of an autumn day is illustrated in Fig. 8. During autumn, cloudiness changes quicker on Crete, thus affecting solar radiation output. Even for these high fluctuating output, the algorithms also provides production stability and capacity credit for the system, which reaches $120 \mathrm{~kW}$.

Apart from the results above, the mean square error (MSE) factor reduction, before and after the algorithm described in Section 4, as well as the peak-to-peak reduction factor are important factors. In Table 4, the average results for each season are listed.

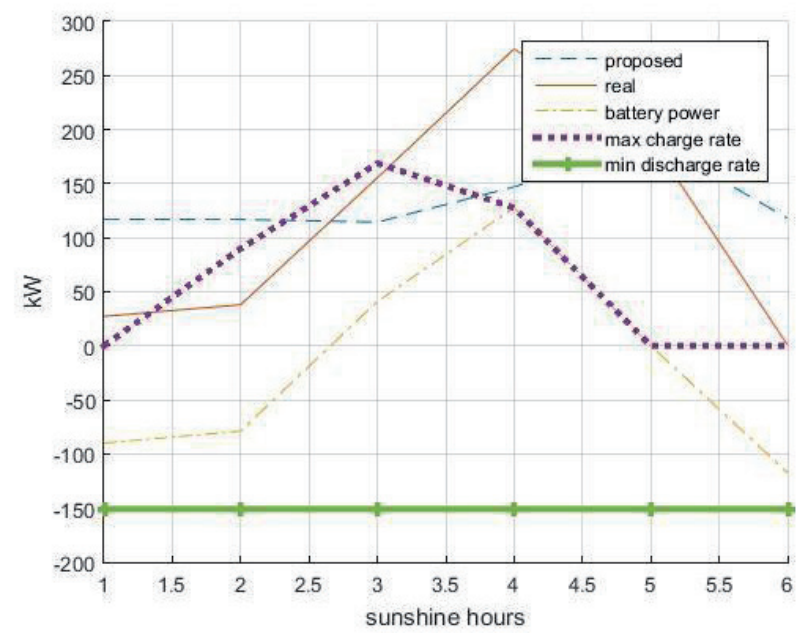

Fig. 8 Comparison of production in an autumn day

Table 4 Mean result for every season

\begin{tabular}{lll}
\hline Season & $\begin{array}{l}\text { MSE reduction } \\
(\%)\end{array}$ & $\begin{array}{l}\text { Peak to Peak } \\
\text { reduction }(\%)\end{array}$ \\
\hline Winter & 72.7 & 72.35 \\
Spring & 93.9 & 17.18 \\
Summer & 95.62 & 16.63 \\
Autumn & 41.43 & 72.13 \\
\hline
\end{tabular}

Regarding the examples above, it is concluded that the installation of the batteries reduces the production volatility to a great extent and achieves capacity credit for a day period, even with some loss of energy and drastically benefits the power grid as a whole, and will benefit more everyone in the future.

Power production volatility reduction has many advantages for all involved members, from the producers to the operator of the island. First of all, regarding the volatility reduction, reducing at the same time the uncertainty of such sources, power grid operators are enabled to include solar dish-Stirling units more easily and frequently in the power production schedule of the grid.

The owner of the Hybrid plant can provide capacity credit to the power system, which can be additionally remunerated as described in the Non-Interconnected Islands Grid Code of Greece [9].

As described above, considerable reduction of production volatility is achievable with relatively low capacity batteries. Thus, the electricity production from RES units should be accompanied by a storage unit of any kind, as this helps mitigating the major disadvantage of RES units, of production volatility. All these actions result to gradually replacing conventional units by RES making the power generation in power systems, especially in island power grids, as eco-friendly as possible and thus the customers and visitors more satisfied.

\section{References}

[1] García-Valladares, O., Velázquez, N. "Numerical simulation of parabolic trough solar collector: Improvement using counter flow concentric circular heat exchangers." International Journal of Heat and Mass Transfer. 52(3-4), pp. 597-609. 2009. DOI: 10.1016/j.ijheatmasstransfer.2008.08.004

[2] Malamatenios, Ch., Vezirgianni, G., Giakoumelos, E., Tsikalakis, A., Tomtsi, T., Hatziargyriou, N. "Concentrated Solar Power (CSP) Technologies and Application in The Middle East \&North Africa (MENA) Countries." In: Proceedings of the DEMSEE Conference, Sitia, Crete, Greece, Sept. 23-24, 2010.

[3] Mingzhen, L., Jinzhong, D. "Modelling and Simulation of Solar Dish-Stirling Systems." In: 2012 Asia-Pacific Power and Energy Engineering Conference. Shanghai, March 27-29, 2012, pp. 1-7. DOI: 10.1109/APPEEC.2012.6307165

[4] Andraka, C. E. "Cost/Performance tradeoffs for Reflectors used in Solar Concentrated Dish Systems." In: ASME 2008 2nd International Conference on Energy Sustainability collocated with the Heat Transfer, Fluids Engineering, and 3rd Energy Nanotechnology Conferences. Jacksonville, Florida, USA, Aug. 10-14, 2008. DOI: 10.1115/ES2008-54048

[5] Mendoza, S., Silva, E., Almazan, O., Guillen, R. "Modeling generation systems from using solar stirling engines parabolic dishes. (Solar/ Dish)." In: World Renewable Energy Forum (WREF) Denver, Colorado, May 13-17, 2012.

[6] Siva Reddy, V., Kaushik, S. C., Tyagi, S. K. "Exergetic analysis and performance evaluation of parabolic dish Stirling engine solar power plant." International Journal of Energy Research. 37(11), pp. 1287-1301. 2013. DOI: 10.1002/er.2926

[7] Nottrott, A., Kleissl, J., Watson, B. "Energy dispatch schedule optimization and cost benefit analysis for grid-connected, photovoltaic-battery storage systems." Renewable Energy. 55, pp. 230-240. 2013. DOI: 10.1016/j.renene.2012.12.036

[8] Dufo-Lopez, R. "Optimization of size and control of grid-connected storage under real time electricity pricing conditions." Applied Energy. 140, pp. 395-408. 2015. DOI: 10.1016/j.apenergy.2014.12.012

[9] Non-Interconnected Island Power Systems (NIIS) Management Code (NIIS CODE), Government Gazette of the Hellenic Republic, B'304-11th Feb.2014. (in Greek) 